\title{
El Tribunal Constitucional como poder político"
}

Peter Häberle

Catedrático de Derecho Constitucional, Filosofia del Derecho y Derecho Eclesiástico del Estado. Universidad de Bayreuth (Alemania).

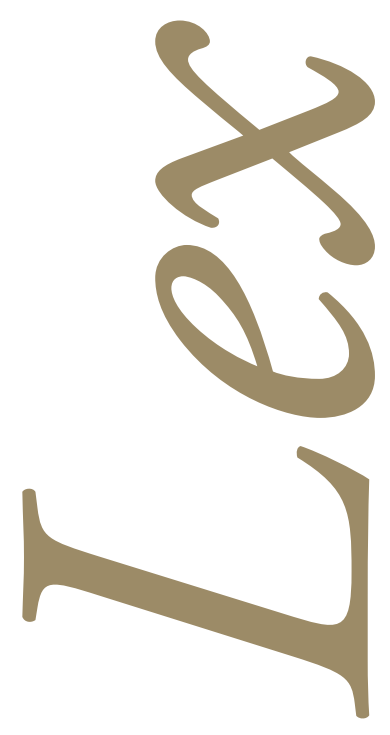

Traducción del trabajo del profesor Häberle "Verfassungsgerichtsbarkeit als politische Kraft -ein Vortrag", en su libro recopilatorio Kommentierte Verfassungsrechtsprechung, Athenäum, Königstein, 1979. Traducción del alemán: Joaquin Brage Camazano. 


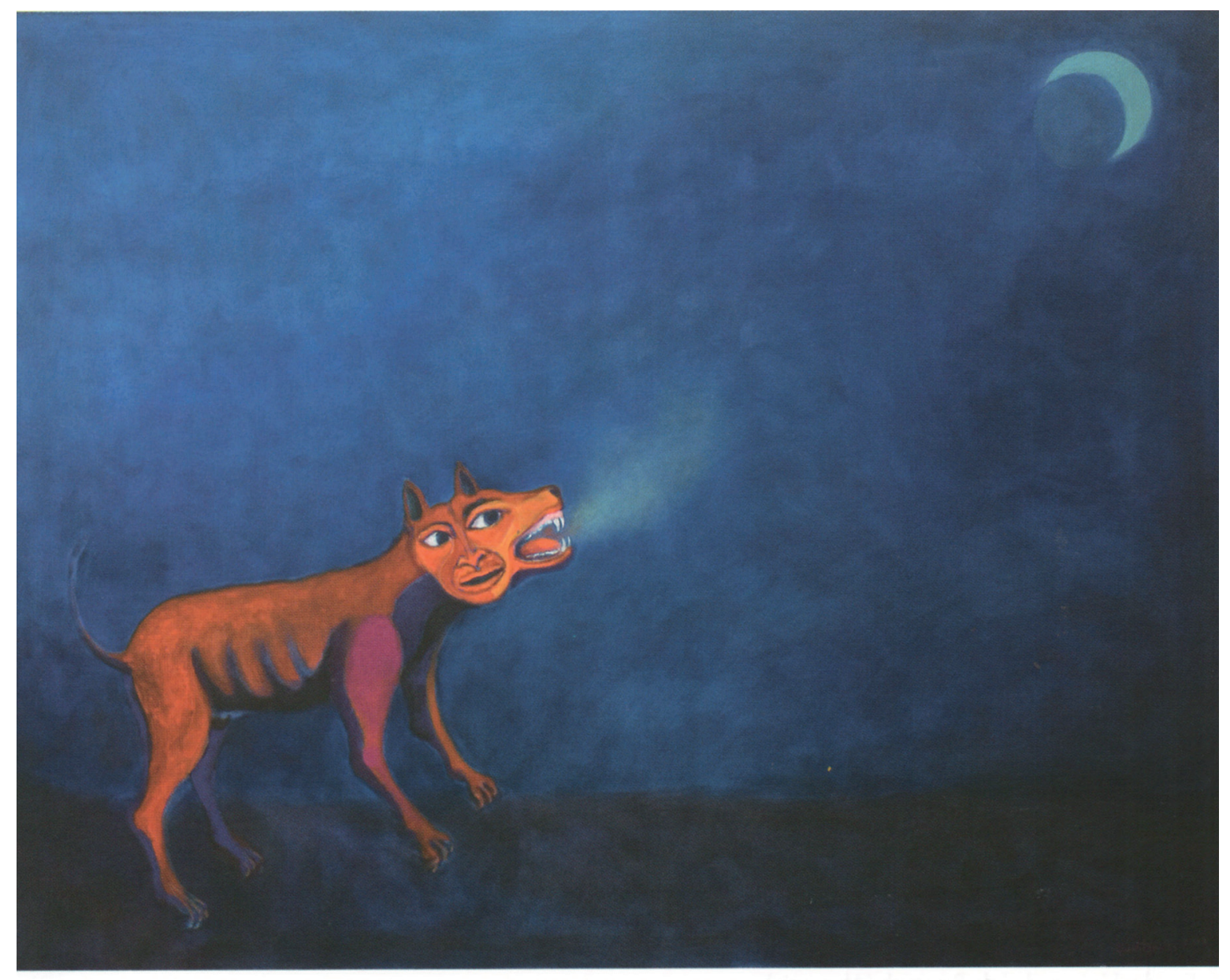

El perro amante de la luna. Óleo, 2006 - 2007 (114 cm. x 146 cm.) 


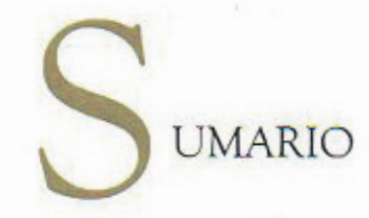

1.- Introducción. 2.- Primera parte: inventario: A.- Grandes competencias/"Grandes" decisiones del Tribunal Constitucional Federal alemán: a.- Recurso constitucional de amparo; b. Control normativo abstracto y concreto; c.- Controversias orgánicas; d.- Controversias federales y competencias para la protección del ordenamiento básico liberal-democrático; B.-Valoración de las construcciones del Tribunal Constitucional; C. - La vinculación de esta conferencia con otras ponencias de esta serie de conferencias. 3.- Segunda parte: Nuevo planteamiento teórico-constitucional: A. El Tribunal Constitucional Federal como "tribunal constitucional", como "tribunal social" sui generis; B.- La jurisdicción constitucional "en” el contrato social: El Tribunal Constitucional Federal como regulador en el proceso continuo de garantía y ajuste de la Constitución como contrato social: a.- La tesis; b.- Material de ejemplo; c.- La exposición detallada; C.- La jurisprudencia del Tribunal Constitucional Federal entre tradición y cambio, entre tradíción y progreso: a.- La cuestión preliminar interdisciplinaria; b. Progreso a través del Derecho judicial constitucional; c.- Los instrumentos para el cambio y el progreso por medio del Tribunal Constitucional Federal; D.- Posibilidades y limites de la funcionalidad del Tribunal Constitucional Federal en el marco de la cultura política del ordenamiento básico liberal-democrático de la Ley Fundamental.

\section{INTRODUCCIÓN}

El Tribunal Constitucional Federal alemán (Tribunal Constitucional Federal alemán, en adelante) está, una vez más, en boca de todos. Muchos son los que han expresado su critica, casi popular: desde el Canciller Federal H. Schmidt, por un lado, quien se encontró con la réplica del Presidente del Tribunal Constitucional Federal: Benda (aquí en Tutzing) de que él no tenía que censurar nada ${ }^{1}$-también Adenauer manifestó ya en su día criticas (con motivo de

1 Frankfurter Allgemeine Zeitung del 3 y 4 de octubre de 1978; reservadamente: H. Schmidt, Frankfurter Allgemeine Zeitung del 5 de diciembre de 1978, p. 10. 
la decisión de la Televisión de 1961) - hasta, por otro lado, las juventudes socialistas -se quejan del gobierno paralelo, el súpergobierno o el contragobierno por el Tribunal'2-; desde los jueces constitucionales viajeros y amigos de hablar en público, como Martin Hirsch en este Ayuntamiento en el verano de 1978, hasta los jueces constitucionales jubilados, como Willi Geiger, quien una y otra vez interpreta de nuevo la decisión sobre las dietas ${ }^{3}$ de la Sala Segunda del Tribunal Constitucional (E 40, 296). Una revista de noticias empieza en el otoño de 1978 una serie propia ${ }^{4}$ y los periódicos están llenos de formulaciones de los pros y los contras.

La crítica muestra en qué medida el Tribunal Constitucional Federal se ha convertido en una pieza básica de la conciencia ciudadana general ${ }^{6}$ (¿más adherida al Estado de Derecho que democrática?), cómo de intensamente -independientemente de cómo decida en el caso concreto- constituye un factor sobresaliente en el proceso político. El reproche estereotipado "una

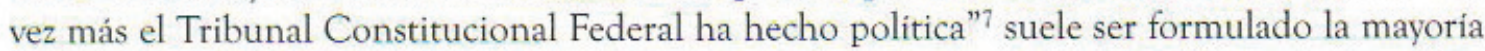
de las veces por aquellos que se consideran en el lado de los perdedores. Sin embargo, visto con rigor, no hay en el Tribunal Constitucional Federal un "ganar" ni un "perder". Entonces, como siempre, el Tribunal decide, juzga en nombre de la Ley Fundamental y es parte del proceso político, lo dirige y es influenciado por él y en él influye: ello se debe a que su objeto es la Constitución de la comunidad politica.

Esta res pública es cosa de todos. La confrontación entre Derecho y Politica, entre función jurisprudencial y función politica, la terminologia "Derecho apolitico" no pueden continuar?.

2 Frankfurter Allgemeine Zaeitung del 20 de septiembre de 1978, p. 5.

3 Se hace referencia a BVerfGE 40,296, sentencia de 5 de noviembre de 1975 en la que, como leading case, el Tribunal Constitucional se pronunció sobre las dietas de los parlamentarios (regionales) desde una perspectiva constitucional, siendo su interpretación controvertida, tanto cientifica como políticamente, hasta hoy (Nota del Traductor).

4 Asi, Der Spiegel número 44, del 30 de octubre de 1978, pp. 38 ss.; número 45, del 6 de noviembre de 1978, pp. 71 ss.; número 46, del 13 de noviembre de 1978, pp. 84 ss y número 47, dél 20 de noviembre de 1978, pp. 78 ss.

5 Véase también Der Spiegel número 16, del 17 de abril de 1978, p. 23: "De guardián a señor" (sobre la decisión sobre la reforma del deber de realizar el servicio militar); H. J. Vogel, en FR del 1 de noviembre de 1978, p. 10; Schueler, en: Die Zeit, del 6 de octubre de 1978, p. 1.

6 De acuerdo a la investigación de opinión pública, el Tribunal Constitucional Federal se halla, hoy como antes, en el puesto número 1 en su valoración: sobre ello, Der Spiegel del 30 de noviembre de 1978, p. 38 (46).

7 Asi, por ejemplo, Der Spiegel número 16, del 17 de abril de 1978, p. 23; véase también Schäfer, diputado y presidente del grupo parlamentario SPD (Partido Socialista de Alemania), que ruega al Tribunal "no aprobar, en su propio interés, decisiones políticas por via de sentencias judiciales" (Frankfurter Allgemeine Zeitung del 2 de octubre de 1978, p. 4); además, el Ministro Federal H.J. Vogel, Die öffentliche Verwaltung 1978, pp. 665 ss.

8 Así, una formulación atinada del Juez retirado del Tribunal Constitucional Federal W. Geiger. Cfr. Frankfurter Allgemeine Zeitung del 9 de octubre de 1978, p. 5

9 Sobre ello, P. Häberle, en: Verfassungsgerichtsbarkeit, 1976, p. 1 (pp. 2 ss.); Stern, Das Staatsrecht der Bundesrepublik Deutschland, tomo I, 1977, p. 19, habla de "simbiosis diferente" entre el Derecho y la politica. 
Debemos buscar otros criterios para la descripción y valoración de las funciones -y las disfunciones-del Tribunal Constitucional Federal.

El polifónico Pro y Contra para decisiones particulares es, en conjunto, una buena señal. "La sociedad abierta de los intérpretes de la Constitución" 10 parte de la competencia de cada ciu. dadano para juzgar y también eventualmente para censurar al Tribunal (por ejemplo, a través de las cartas al Director). Con razón decía el vicepresidente del Tribunal Constitucional Federal, W. Zeidler, en su día candidato favorito (con éxito) a juez del Canciller federal H. Schmidt, en el $15^{\circ}$ Coloquio de Cappenberger (1978), que el Tribunal Constitucional Federal queda en principio expuesto a cualquier crítica, pero cuando donde se manifestaban miembros de otro órgano constitucional, también por ejemplo el canciller federal en su condición de tal, el derecho a la crítica encuentra límites ${ }^{11}$. Como de costumbre, el límite entre la crítica (ilícita) en salvaguardia de la responsabilidad oficial de un órgano constitucional y la crítica lícita de un político como persona hay que determinarlo -Zeidler propone una orientación al juicio sobre las relaciones públicas del Gobierno ${ }^{12}-$, tal crítica es tan censurable como oscilante fue el péndulo entre judicial activism y judicial restraint en el pasado ya en el Tribunal Supremo de los Estados Unidos de América, y como en el futuro habrá de serlo también entre nosotros. Una vez más, debemos en principio poner de relieve lo positivo de esta discusión: el Tribunal Constitucional Federal tiene un lugar ("su" lugar), a delimitar, como de costumbre, en el centro de la realidad constitucional federal alemana y en su cultura política, tanto en la (joven) historia de esta República como en el presente; ocupará también este lugar en el futuro con sus especiales problemas generacionales. Y si bien nadie podría "maltratar de obra" al Tribunal Constitucional Federal como institución, algunas de sus competencias en particular pueden ser reconsideradas (por ejemplo, el control normativo abstracto). De esta forma, se hace patente un aspecto más amplio: el de la innovación y la transformación, el de la tradición y la historia, que determina el marco de este ciclo de conferencias interdisciplinarias inauguradas por Josef Becker.

Las siguientes consideraciones se basan en un doble paso: la primera parte sirve como inventario; se plantea qué es lo que ha hecho el Tribunal Constitucional Federal juridica y politicamen.

10 Sobre este tema, mi bosquejo: "Die offene Gesellschaft der Verfassungsinterpreten", Juristenzeitung 1975, pp. 297 ss, ahora en: Verfassung als offentlicher Proze $\beta$, 1978, pp. 155 ss. INota del Traductor: Las ideas del autor sobre este punto pueden verse en su libro El Estado constitucional, UNAM, estudio introductorio de D. Valadés y traducción e indices de H. Fix Fierro, México, 2001, pp. 149 ss].

11 Frankfurter Allgemeine Zeitung del 30 de octubre de 1978, p. 4. Cfr. la respuesta del Presidente del Tribunal Cons. titucional Federal Benda a la crítica a la sentencia de H. Schmidt: "No puede ser tarea del Jefe del Gobierno Federal hacer criticas al tribunal supremo del pais" (Frankfurter Allgemeine Zeitung del 3 de octubre de 1978) así como la contracritica del Juez retirado del Tribunal Constitucional Federal (Frankfurter Allgemeine Zeitung del 9 de octubre de 1978 , p. 5). Sobre la controversia, véase también Massing, ZParl, 1979, pp. 119 ss.

12 Frankfurter Allgemeine Zeitung del 30 de octubre de 1978, p. 4; sobre la sentencia (E 44, 125): P. Häberle, Juristenzeitung, 1977, pp. 361 ss. 
te en el campo de las relaciones tirantes entre "tradición y transformación en los treinta años de la República Federal de Alemania".

La segunda parte esboza un nuevo planteamiento teórico-constitucional con la finalidad de contemplar al Tribunal Constitucional en la triada del pluralismo -que garantiza de la libertad-, esto es, los derechos fundamentales, la separación de poderes y el federalismo y situarlo, por medio de la figura del "contrato social", en las profundidades históricas de un modelo clásico de pensamiento para construirle, en el contrato generacional, la oportunidad de un puente hacia la generación venidera. Ambas cosas pueden aqui sólo ser esbozadas.

Un aliciente particular, pero también una especial dificultad, subyace en el hecho de que una conferencia sobre el Tribunal Constitucional Federal en este foro, en el Ayuntamiento de Augsburgo, se dirige no solo a juristas, sino también a los ciudadanos: el Tribunal Constitucional federal es un "tribunal civil" par excellence (no solo cuando los ciudadanos tienen acceso a él por medio del recurso de amparo); ello exige la aproximación del lenguaje técnico al lenguaje ordinario como ha logrado ocasionalmente el propio Tribunal Constitucional Federal, por ejemplo en la sentencia Lüth (E 7, 198), como debe lograrse, ante todo, en las decisiones sobre derechos fundamentales ${ }^{13}$, y como puede solo lograrse si nosotros nos lo proponemos con toda honestidad.

\section{PRIMERA PARTE: INVENTARIO}

A.- Grandes competencias/"Grandes" decisiones del Tribunal Constitucional Federal alemán

En la Ley Fundamental están reguladas las competencias del Tribunal Constitucional Federal de un modo único en el mundo. Se habla (críticamente) del Tribunal Constitucional Federal como "guardián" o, incluso, como "señor" de la Constitución ${ }^{14}$, como "cuarto" o incluso "primer poder", como "soberano secreto", etc. Antes de cualquier valoración global es preciso examinar las "grandes" competencias del Tribunal Constitucional Federal y las "grandes decisiones", con las que se ha desarrollado esencialmente la Ley Fundamental desde 1951.

a.- Recurso constitucional de amparo

13 Peter Häberle, "Recht aus Rezensionen", en su libro Kommentierte Verfassungsrechtsprechung, Athenäum, Königstein, 1979 , pp. 1 ss.

14 En contra, Leibholz, Frankfurter Allgemeine Zeitung del 8 de noviembre de 1978, p. 10: "Guardián, no señor de - la Constitución". 
El primer lugar corresponde al recurso constitucional de amparo (artículo 93.1, número 4a de la Ley Fundamental). Esta competencia convierte al Tribunal Constitucional Federal en el "tribunal de los ciudadanos". El acceso que este recurso proporciona, "libre de cargos y sin asesoramiento de un abogado", a cualquiera al Tribunal Constitucional Federal (Rupp-v. Brünneck) ha anclado profundamente al Tribunal en la conciencia de los ciudadanos y ha fortalecido la autoconciencia civica frente al poder público. La cuota de éxito es tan pequeña en una consideración puramente numérica (ejemplo numérico: de 36000 recursos constitucionales de amparo entrados fueron estimados 400, esto es, un $1,11 \%$ ), como grande es el efecto pedagógico y democratizador para los ciudadanos del recurso constitucional de amparo. Cualquiera puede plantearlo, con agotamiento previo de la via judicial ordinaria, con la afirmación de haber sido lesionado por el poder público en uno de sus derechos fundamentales o derechos equiparados a estos. Una decisión central que ha tenido lugar por vía de un recurso constitucional de amparo (muy politizado) y que posee en la práctica el rango de la Ley Fundamental es la famosa sentencia del caso "Lüth" (E 7, 198) ${ }^{15}$ con su efecto hasta en la Sentencia del caso "Lebach" ${ }^{16}$ (E $35,202)$. Produce efectos con su método de la ponderación de bienes bastante más allá del artículo 5 de la Ley Fundamental ${ }^{17}$. Hay que mencionar también la Sentencia sobre las farmacias $(E 7,377)^{18}$ y la primera Sentencia del numerus clausus [en el acceso a la universidad] (E 33, 303), asi como las decisiones sobre la audiencia juridica y el proceso justo [recientemente $\mathrm{E} 47,182$ (187) y E 46, 325 (334 ss.)] y, por último, sobre la juridificación del status especial.

\section{B.- Control normativo abstracto y concreto}

El control normativo concreto y abstracto son, por su parte, de elevada significación política y práctica. A instancias, por ejemplo, del Gobierno Federal o de un tercio de los miembros del Bundestag (iprotección de minorías!), una Ley Federal puede ser sometida al examen del Tribunal Constitucional Federal en cuanto su compatibilidad con la Ley Fundamental. Por esta vía del control normativo abstracto (articulo 93.1, número 2, de la Ley Fundamental) han tenido lugar "sentencias constructivas", como la primera sentencia sobre financiación de los partidos políticos (E 20, 56).

15 Sentencia que consagra la eficacia indirecta de los derechos fundamentales frente a particulares (nota del Traductor).

16 Sentencia relativa a un caso en que hubo que ponderar entre el libre desarrollo de la personalidad (resocialización) de un preso a punto de acabar de cumplir una condena y la libertad de información de una cadena de televisión, que programaba un reportaje sobre los hechos criminales por los que el solicitante de amparo habia sido condenado unos años antes (nota del Traductor).

17 Sobre ello, por ejemplo, la discusión en el Coloquio de Múnich en honor de H. Spanner, 1979, pp. 64 ss., 68 ss.

18 Esta sentencia se referia a la fijación por el legislador regional de una serie de requisitos para ejercer como farmacéutico restrictivos de la libertad de profesión (nota del Traductor). 
En el caso del llamado control normativo concreto (articulo 100 de la Ley Fundamental), también llamado "demanda judicial", la cuestión la plantea un tribunal, por ejemplo un tribunal de distrito, ante el Tribunal Constitucional Federal (ejemplos: la decisión sobre la igualdad de derechos del hombre y la mujer, E 3, 225; E 45, 187, sobre la constitucionalidad de la cadena perpetua o la decisión sobre el articulo 7 de la Ley Atómica; cfr. E 47, 146 y E 49, 89).

\section{c.- Controversias orgánicas}

Las controversias orgánicas (artículo 93.1, número 1, de la Ley Fundamental) han llevado, por ejemplo, a la sentencia sobre la publicidad electoral, así como a la decisión sobre el pre-

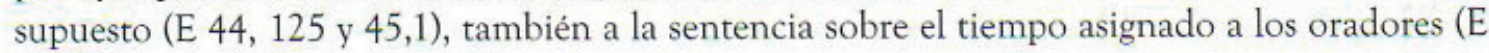
$10,4)$.

d.- Controversias federales y competencias para la protección del orden básico liberal-democrático

De las otras muchas competencias, menciónese la decisión de controversias federales (articulo 93.1, número 3 de la Ley Fundamental), así como para la defensa frente a los enemigos del orden básico liberal democrático ("protección constitucional"). Palabra clave: prohibición de partidos, artículo 21.2 de la Ley Fundamental y pérdida, articulo 18 de la Ley Fundamental. Son básicas desde un punto de vista de teoria de la democracia tanto la sentencia sobre el SRP (Partido Socialista del Imperio) como la decisión sobre el KPD (Partido Comunista de Alemania): E 2,1 (12 ss.) y E 5, 85 (196 ss.) y, en mi opinión, también la decisión sobre las dietas [de los parlamentarios] (E 40,296), criticada en ocasiones como un control normativo abstracto con el ropaje de un recurso constitucional de amparo.

\section{B.- Valoración de las construcciones del Tribunal Constitucional}

$\mathrm{Si}$ se buscan los puntos de vista supremos con los que los jueces del Tribunal Constitucional Federal han hecho "historia" hasta hoy, se llega a:

a. Las decisiones sobre derechos fundamentales y sobre el Estado de Derecho (por ejemplo, casos "Lüth", "Blinkfüer"19 (E 7, 198; 25, 256), asi como las decisiones a los derechos fundamentales procesales: artículos 101-104 de la Ley Fundamental, en especial en interés de un proceso justo (por ejemplo, E 46, 202, 209 ss; 325, 334 ss.);

19 Esta sentencia se refería a un caso en que por una Editorial, poco después de la construcción del muro de Berlin, se había llamado al boicot a los vendedores de periódicos de Hamburgo para no vender los editados por una - empresa que emitia la programación radiofónica de la República Democrática Alemana (nota del Traductor). 
b. Las decisiones sobre el federalismo y la división de poderes (por ejemplo, la sentencia sobre la televisión: E 12, 205), que son dos manifestaciones del pluralismo;

c. La jurisprudencia sobre la oposición y sobre la protección de las minorias en la democracia indirecta: caso de los Testigos de Jehová (E 23, 127, 191); también la institución del voto paricicular pertenece a este sector, al igual que la jurisprudencia de la tolerancia (en Derecho Eclesiástico del Estado: E 41, 65, 78; 65, 83; 88, 108 ss., pero también E 47, 46, 76 ss).

Ciertamente, surge ahora la cuestión de si el Tribunal Constitucional Federal se ha ajustado él mismo siempre con la suficiente moderación al conjunto de los "pesos a equilibrar" (equilibrio estructural y funcional de poderes).

En conjunto, todas estas decisiones favorecen al final al pluralismo politico: la jurisdicción constitucional como "jurisprudencia del pluralismo". El Tribunal Constitucional Federal opera como fuerza juridica y como fuerza política. El balance parece básicamente positivo, simplemente un poco deficitario (a lo sumo en la Sentencia "Mephisto": E 30, 173, asi como, por ejemplo, en E 44, 1972).

Unas palabras sobre la historia del efecto politico de las grandes decisiones a partir de grandes competencias. Hablando politicamente, el Tribunal Constitucional Federal, en la sentencia sobre la televisión, ha sujetado a límites a la "democracia de Canciller" y ha fortalecido a la Oposición ${ }^{21}$, asi como también al federalismo y a la libertad protegida por los derechos fundamentales. Asi como antes Hesse habia hecho frente con éxito, con K.A. Zinn, "contra Bonn" (ejemplos: financiación de los partidos politicos: E 20, 56; controversia de las escuchas telefónicas: E 30,1 , etc.), las "iniciativas de Baviera" sirvieron y sirven recientemente y hoy con frecuencia al federalismo ${ }^{22}$; con otras palabras: los contrapesos de los Länder frente a la Federación, de las minorias (de la oposición) frente a las mayorias, de los individuos frente a los grupos o el establishment (jlas iglesias! ${ }^{13}$ ) surten efectos sobre la jurisdicción constitucional. ¡Esta se transforma en la garantia del pluralismo ${ }^{24}$ !

20 La problemática del triunvirato no puede ser aqui tratada.

21 Sobre el concepto "jurisprudencia de la oposición": H.P. Schneider, Die parlamentarische Opposition im Verfas. sungsrecht der Bundesrepublik Deutschland, I, 1974, pp. 225 ss. Desde luego, hay que objetar con H. J. Vogel, FR del 1 de noviembre de 1978, p. 10, que la oposición apenas puede ser llevada ante el Tribunal Constitucional Federal, con lo cual se ha de dar ante la opinión pública la impresión de que el Tribunal Constitucional Federal y la oposición simpatizan más que el Tribunal Constitucional Federal y el Gobierno.

22 Por ejemplo, E 37, 363.

23 Cfr. E 23, 127, 191; 32, 98; 33, 23; 35, 366; 44, 37.

24 No es posible aquí, lamentablemente, entrar más a fondo en la sentencia sobre el Tratado Básico $(E$ 36, 1) y sus aspectos totalmente alemanes (esperanzas, posibilidades, limites). Véase, por último: "Fūnf Jahre Gundvertragsurteil des BVerfG", Simposio: Finis Germaniae, 1979. 
"Lo politico" se entiende aquí ampliamente: se caracteriza por su relación potencial o actual con la res publica en su conjunto, ya que los diferentes conceptos de lo politico hasta ahora han absolutizado elementos parciales individuales: por ejemplo, el elemento del poder, el ingrediente del bienestar o de la felicidad o el aspecto de lo irracional o de lo dinámico. Todas las funciones estatales son funciones politicas en este sentido. Se diferencian por la manera y modo en que actúan en el marco de la división republicana de trabajo, pero no se "contraponen" al Derechoo o algo parecido. También el legislador democrático interpreta la Constitución, también el juez (por ejemplo, especialmente tangible en el caso del Tribunal Federal del Trabajo en el Derecho de los conflictos laborales) es un poco "poder politico". El Derecho y la politica no se contraponen uno al otro en el Estado constitucional democrático, son aspectos parciales, funciones parciales de la res pública en su conjunto.

Muchos hablan de "pasos fronterizos" del Tribunal Constitucional Federal en atención a lo político ${ }^{25}$, pero nadie ofrece hasta ahora una clara separación de Derecho y política. Ello no puede asombrar, en realidad no se puede encontrar. También las buenas decisiones para tornar efectivos los derechos fundamentales son politica, en concreto, "politica de los derechos fundamentales" ${ }^{\prime 26}$. Se puede tratar de los diferentes modos, bien sólo cuantitativos, bien solo juridico-funcionales, en los que un tribunal constitucional ejerce politicamente frente al legislador, a duras penas se puede reconocer una diferencia cualitativa.

C. La vinculación de esta conferencia con otras ponencias de esta serie de conferencias

Las conexiones internas con temas particulares de este ciclo de conferencias son evidentes:

Con el tema de Theo Stammen (Tradición y cambio de la cultura política en la República Federal Alemana): la jurisdicción constitucional es más que un reflejo de la (compleja) cultura politica en la República Federal de Alemania; es factor conformador, por ejemplo para la actuación de los órganos estatales, partidos o ciudadanos unos respecto de otros.

Con el tema "Iglesia en una sociedad secularizada" (Karl Forster): el Tribunal Constitucional Federal ha adoptado decisiones básicas sobre el Derecho Eclesiástico del Estado ${ }^{27}$ en las que tanto ha "derogado" la tradición de Weimar (legitimado para ello en el artículo 140 de la Ley

Sobre este concepto, P. Häberle, VVD

castellano, vése $P$. Häberle, Pluralismo y Constitución. Estudios de Teoria Constitucional de la sociedad abierta Tec nos, estudios preliminar y traducción de E. Mirkunda, 2002, Madrid, pp, 161 ss].

27 Sobre ello, el informe de Hollerbach, Archiv des öffentlichen Rechts, 92 (1967), pp. 99 ss.; véase, además, BVerfGE 30,$415 ; 41,29 ; 42,312 ; 44,37$. Sobre el conjunto, véase también mi contribución: "Staatskirchenrecht als Religionstecht der verfaßten Gesellschaft" (1976), ahora en: Verfassungs als öffentlicher Prozeß, 1978, 329 ss. 
Fundamental) como también ha aprobado innovaciones en el campo del Derecho Eclesiástico del Estado (sobre la interpretación del artículo 4 de la Ley Fundamental), por ejemplo la idea de la "neutralidad confesional ideológica" del Estado (desde E 12, 1, 4). Las Iglesias son tratadas aquí "como" grupos pluralistas (pero véase también E 42, 312, 333).

Con "el dominio de las élites en la democracia pluralista" (Peter Waldmann): la acreditada "interpretación constitucional pluralista" del Tribunal Constitucional Federal ${ }^{28}$ es un intento de este de contrarrestar un déficit de pluralismo creado de algún modo por un "señorio de las élites” en la República Federal o no evitado. Desde luego, el Tribunal Constitucional Federal depende aqui en especial medida del proceso político.

Con el orden económico (Reinhard Blum), respecto del cual el Tribunal Constitucional Federal no solo ha dictado sentencias políticamente controvertidas hasta hoy (sobre todo, la sentencia sobre las ayudas a las inversiones: E 4, 7, 17 ss), también fue capaz incluso de dar impulso a la discusión científico-económica. El Tribunal Constitucional Federal concede al legislador en el ámbito de la política económica un margen notablemente amplio ${ }^{29}$ : la "economía social de mercado" no está, como tal, protegida con rango constitucional, ¡a diferencia ahora del artículo 33 de la nueva Constitución española $(1978)^{30 !}$

También hay, finalmente, contactos con el tema de Helmut Koopmann: "Literatura comprometida políticamente después de 1945". En este articulo, el Estado (la República de Bonn) aparece solo de forma totalmente negativa. Dicho con otras palabras, la literatura jurídica sobre la jurisdicción constitucional no encuentra a través de la literatura politicamente comprometida ni apoyo ni eco, lo que es un déficit lamentable de nuestra cultura política. Pero como jurista habrá que cuestionarse también con autocrítica: asi se ha frenado bastante la sentencia Mephisto $^{31}(E 30,173)$. En la literatura alemana sería bastante dificil encontrar un escritor que elaborara para la Ley Fundamental una contribución comparable al Preámbulo de Muschg sobre el Proyecto de Constitución suiza de 1977. Ciertamente, ¿lo buscariamos también nosotros, los juristas?

28 Sobre ello, P. Häberle, en: Verfassung als offentlicher Prozess, pp. 124, 130, 136, 193 ss.

29 Cfr. E 4, 7 (13 ss., 17 ss.), jurisprudencia constante.

30 De la literatura, cfr., por ejemplo, Saladin/Papier, VVDer SpiegeltRL, número 35 (1977), pp. 1 ss., con más referencias; Badura, Juristische Schulung, 1976, pp. 205 ss. La cuestión es si hay un economical self-restraint (Spanner, Die öffentliche Verwaltung, 1972, pp. 217 ss.) y si es así, por qué razones: ¿por qué hay que otorgar la primacia al poder de conformación de la economia y al del legislador democrático? (véase, además, Schmidt-Preu $\beta$, Verfas. sungsrechtliche Zentralfragen staatlicher Lohn und Preisdirigismen, 1977, pp. 82 ss., 122, 144 ss.; Scholz, Zeitschrift für das gesamte Handelsrecht und Wirtschaftsrecht 141 (1977), pp. 520 ss).

31 Sentencia relativa a la libertad artística y a la protección póstuma del honor (prohibición a una editorial de copiar, vender y publicar una biografia sobre un artista de teatro muy significado del nazismo ya fallecido, que sale bastante mal parado en la misma) (nota del Traductor). 


\section{SEGUNDA PARTE: NUEVO PLANTEAMIENTO TEÓRICO-CONSTITUCIO-} NAL

El -vasto- inventario muestra cómo el Tribunal Constitucional Federal ha contribuido desde 1951 a la construcción de nuestra comunidad de libertad.

El modelo del pluralismo científico, elaborado teórico-cientificamente sobre todo por Karl Popper ("La sociedad abierta y sus enemigos"), entre otros, contra el marxismo, constituye un marco de valoración de elevadas pretensiones y asimismo una realidad solo puntualmente deficiente $^{32}$, modelo que desde la perspectiva constitucional continúa en una teoria constitucional pluralista ${ }^{33}$.

¿Qué debe, qué puede hacer el Tribunal Constitucional Federal en el marco de la cultura politica?

El siguiente ensayo pretende investigar esta cuestión bajo dos epigrafes: bajo el de la cualidad del Tribunal Constitucional Federal como "tribunal constitucional", es decir, como un tribunal que comprende al Estado y la sociedad (A) y el aspecto de situar al Tribunal Constitucional Federal en el continuo proceso de protección y actualización (acreditación) del contrato social de la Ley Fundamental (sobre todo como contrato generacional) para salirse del estéril "o ... o" de la función juridica o politica (B). Después de unas consideraciones sobre la jurisprudencia del Tribunal Constitucional Federal en el campo de las relaciones tirantes entre tradición y transformación (C) serán examinadas finalmente las posibilidades y los limites de la funcionalidad de un tribunal constitucional en la cultura politica de Alemania (D).

A.- El Tribunal Constitucional Federal como "tribunal constitucional", como "tribunal social" sui generis

Formalmente considerado, el Tribunal Constitucional Federal Alemán (Tribunal Constitucional Federal alemán, en adelante) tiene todas las características de un tribunal, en su propia terminología (sobre esto, BVerfGE 18, 241), "estatal" ${ }^{34}$, es decir, se basa en una ley estatal y el Estado regula, o influye en, el nombramiento de los jueces. Es, sin embargo, bastante más: es un tribunal constitucional, es decir, competente para controversias materialmente constituciona-

\footnotetext{
Cfr., por ejemplo, BVerfGE 44, 197 respecto de Geiger, pp. 209 ss.
}

P. Häberle, Verfassung als öffentlicher Prozess, pp. 121 ss., 140 ss.

${ }^{34}$ Sobre ello, veáse E 18, 241 y mi comentario jurisprudencial en: Die öffentliche Verwaltung, 1965, pp. 369 ss., ahora en: Kommentierte Verfassungsrechtsprechung, 1979, pp. 347 ss; véase también E 22, 42; 26, 186; 48, 300 (315 ss). 
les especificadas enumerativamente ${ }^{35}$. El peso total de esta afirmación se aclara sólo a partir de una precisión del concepto de Constitución. Una «Constitución» es el ordenamiento básico de Estado y sociedad; no es solo restricción del poder estatal (H. Ehmke), sino también restricción del poder social y es habilitación al poder estatal. Comprende al Estado y la sociedad ${ }^{36}$. La jurisdicción constitucional como fuerza política opera desde un principio más allá del dogma de la separación Estado/sociedad.

El hecho de que el Tribunal Constitucional Federal alemán sea un "tribunal constitucional" del conjunto de la res pública, tiene consecuencias muy concretas para cuestiones particulares, por ejemplo respecto de la recusación de los jueces ${ }^{37}$ [sobre ello, BVerfGE 35, 171 (246); 89,28]; tiene, además, como consecuencia que el Tribunal no se puede amarrar a una teoría o Escuela, sino que debe esforzarse por una integración pragmática de elementos teóricos.

Esta relación materialmente constitucional de la jurisdicción constitucional tiene consecuencias sustantivas y procesales, por ejemplo, en su compromiso con el modelo del pluralismo y en la exigencia de construir el Derecho procesal constitucional a la vista de los instrumentos pluralistas de información y participación ${ }^{38}$.

La creciente politica del Tribunal Constitucional Federal ${ }^{39}$ de adquisición de información plural hay que verla en este contexto. También la elección de los jueces constitucionales, del espectro de todos los partidos (y es de esperar que en el futuro vaya más allá de estos ${ }^{40}$ ), inserta de un modo efectivo al pluralismo en el proceso constitucional (y ejerce una influencia sobre él). Ello es presupuesto para un timonaje de la sociedad por parte del Tribunal Constitucional y "su" Derecho. Aquí se produce un efecto recíproco, cuanto más interviene el Tribunal Constitucional Federal alemán en el proceso de conducción de la sociedad abierta, tanto más se adhiere la sociedad a él, quiere hacerse escuchar "en Karlsruhe" [sede del Tribunal Constitucional Federal alemán]. Hasta qué punto es asi se comprobó en el asunto de la cogestión: casi se percibian (1978) las líneas de fuerza de la opinión pública de la sociedad en la Sala de sesiones (BVerfGE 50, 290).

35 En detalle, P. Häberle, en: id., Verfassungsgerichtsbarkeit, 1976, pp. 9 ss, 34 ss.

36 Sobre este concepto constitucional, mi co-informe en VVDer SpiegeltRL, número 30 (1972), p. 43 (pp. 56 ss.); véase tambiẻn Sur, en: Der Staat, número 17 (1978), p. 369 (384 ss.).

37 Sobre ello, veáse BVerfGE 35, 171, 246, y mi comentario jurisprudencial en: Juristenzeitung, 1973, pp. 451 ss; ahora en: KVR, número $15 \mathrm{a}$, pp. 405 ss.

38 Detalles ibidem, número $15 \mathrm{~b}$, pp. 414 ss.

39 Cfr. mis referencias en Juristenzeitung, 1976, p. 377 (382 ss).

40 ¿Buenos planteamientos para ello se encuentran en la elección de jueces del Tribunal Constitucional Federal de 1975 ! 
Este planteamiento conduce a un "nivel" ulterior. Hay que ver al Tribunal Constitucional Federal alemán en su relación intensa con la totalidad de la sociedad: es un "tribunal social" sui generis y en sentido amplio. A través de su jurisprudencia se abre a la variedad de ideas e intereses -la asume-, y viceversa, guia él a la sociedad. Considerando la elección de los jueces, la aplicación de su Derecho procesal constitucional y los resultados materiales de la interpretación lpor ej., en la estructuración de aspectos parciales de la sociedad sobre el "efecto frente a terceros" de los derechos fundamentales, últimamente BVerfGE 95, 28 (37)], es más un Tribunal del conjunto de la sociedad que uno "estatal". ¡Ello tiene consecuencias de más alto nivel, pero también para el trabajo diario del Tribunal!

El Tribunal Constitucional Federal alemán y su Derecho procesal consiguen una relación de tipo único con la sociedad.

Su actividad -transformadora de Estado y sociedad - se deriva en un sentido general de que es el Tribunal de la Constitución -y la Ley Fundamental regula no solo al Estado, sino también, en su estructura básica, a la sociedad, a la que transforma en "sociedad constituida" 41 . De un modo específico, el Tribunal Constitucional Federal alemán actúa, además, de manera muy especial y consciente, intensiva y amplia en el ámbito de la res publica, entre el "Estado" y el "particular", al que se puede llamar la "sociedad" o el ámbito de lo público -pluralista-42. Así se muestra no solo en la efectivización de los derechos fundamentales desde la vertiente procesal $^{43}$, sino también, en su práctica procesal, al servirse cada vez más de los instrumentos de información y participación del Derecho procesal constitucional. Adquiere informaciones a través de una diferenciada praxis de audiencias y de formas niveladas de participación con relación a los grupos pluralistas, organizaciones como el $\mathrm{DGB}^{44}$, las Confederaciones de empresarios y las Confesiones religiosas, etc ${ }^{45}$. Con ello, "penetra" el Tribunal en el ámbito de la sociedad, asume ideas e intereses de ese ámbito, los "oye" y los transforma por medio de su interpretación constitucional abierta. Por esta vía es apoyado por la doctrina cientifica. El Derecho procesal constitucional se abre a la "sociedad abierta de los intérpretes constitucionales"; se transforma en su "médium", sobre todo alli donde el Parlamento ha fallado.

Del mismo modo que el itinerario de la ley parlamentaria fue históricamente, y es (también en el Estado constitucional), el intento de una transformación de lo social en lo estatal, se constatan ahora fenómenos -limitadamente- paralelos en los procesos ante el Tribunal constitucional.

41 Sobre ello,, véase mi Conferencia como invitado en: P. Häberle, Verfassung als öffentlicher Prozess, pp. 122 ss.

42 Sobre ello, P. Häberle, Öffentliches Interesse als juristisches Problem, 1970, pp. 708 ss. La Constitución estructura el proceso público, no es absorbida por él.

43 Sobre ello, E 46, 325 (333).

44 DGB es el «Deutscher Gewerkschaftsbund o Confederación de Sindicatos Alemanes (Nota del Traductor).

45. Para referencias, véase la nota 32 y actualmente de nuevo BVerfGE 50, 57 (69 ss.); 51; 115 (119 ss). 
Formulado de otro modo, el Tribunal Constitucional Federal alemán se aproxima a la sociedad de dos modos: la guia de manera creciente por medio de su copiosa jurisprudencia (por ej., sobre el "efecto frente a terceros" y la objetivización de los derechos fundamentales), la estructura y la transforma, a su manera, en una parte de la "sociedad constituida". Justamente a causa de esta relación con la sociedad se ve en la necesidad de llevar en su Derecho procesal a la sociedad ante su foro: así puede comprobarse en la praxis de información y participación pluralistas, sobre todo en los "grandes procesos" [como en el proceso del numerus clausus: BVerfGE 33,303 (318 ss.)], pero también en procesos mas pequeños. Llevado al extremo, puede formularse: el Tribunal Constitucional Federal alemán gana un poco el carácter de un "tribunal de (toda) la sociedad" de un tipo especial ${ }^{46}$. Pierde en la tradicional estatalidad en la medida en que es un factor en el proceso de constitución de la sociedad. Es un "tribunal constitucional" más allá de la separación del Estado y la sociedad, de los tribunales estatales y "sociales" (como los llamados tribunales deportivos). El Tribunal Constitucional Federal alemán se toma en serio a la "sociedad abierta de los intérpretes constitucionales": no solo procedimentalmente, es decir, en el Derecho procesal constitucional ${ }^{47}$, sino también materialmente, en su interpretación constitucional, en la que se hace eco de manifestaciones del Gobierno federal (por ej., declaraciones gubernamentales), de la propia comprensión de las confesiones religiosas (BVerfGE 42, 312 (331); 46, 73 (95)] o de argumentos de una asociación como la Confederación "Libertad de ciencia" o de una institución como el Consejo de la Ciencia ${ }^{48}$.

B. La jurisdicción constitucional "en" el contrato social: El Tribunal Constitucional Federal como regulador en el proceso continúo de garantía y ajuste de la Constitución como contrato social

a.- La tesis

La tesis dice asi: el Tribunal Constitucional Federal tiene una responsabilidad especifica mancomunada en la garantía y actualización de la Constitución como contrato social, codirige su proceso continuo, está vinculado al respecto por el principio del pluralismo.

El modelo de contrato social -patrimonio clásico común europeo- es, en el sentido aqui utilizado, un modelo de pensamiento, un principio heurístico con el fin de garantizar la libertad personal y la justicia pública. No es ciertamente ninguna "horma" con arreglo a la cual se pueda tallar toda la realidad de una Constitución como proceso público; pero puede dar respaldo

46 Pero no en el sentido de tribunales sociales socialistas; sobre ello, Eser, Gesellschaftgerichte in der Strafrechtspflege, 1970.

47 Sobre ello, mi contribución en Juristenzeitung, 1975, pp. 297 ss.; también en: Verfassung als öffentlicher Prozess, pp. $155 \mathrm{ss}$

45 cfr. BVerfGE 47, 327 (384ss.) 
al adecuado dominio de dichas cuestiones políticas o jurídico-constitucionales básicas libre de "ideologias unilaterales" 49 . Su extensión al Tribunal Constitucional puede parecer osada a algunos; hasta donde sé, no se ha ensayado hasta ahora. El contrato social es tan viejo como relativamente joven es la (independizada) jurisdicción constitucional. Uno y otra no han sido todavia puestos en relación recíproca. Esta puede ser una oportunidad. Debía ser aprovechada. La teoría clásica del contrato social ha servido a lo largo de la historia como modelo de explicación y justificación de los más diferentes contextos (desde J. Locke hasta J.J. Rosseau, desde I. Kant hasta la discusión sobre el consenso básicic ${ }^{50}$ ). ¿Por qué no iba a poder desplegar un valor informativo para nuestros problemas, para las cuestiones de la jurisdicción constitucional, para la actualización de la Constitución?

\section{b.- Material de ejemplo}

Un pensamiento sobre el contrato social puede servir muy concretamente como planteamiento para la critica a, y para el acuerdo con, algunas decisiones del Tribunal Constitucional Federal.

a) Doy en primer lugar ejemplos para la critica. Si se observa en conjunto una pluralidad de decisiones del Tribunal Constitucional Federal, sobre todo recientes: la sentencia sobre el artículo $218^{51}(\mathrm{E} 39,1)$, la decisión de los radicales ${ }^{52}(\mathrm{E} 39,334)$ y la decisión sobre el deber de realizar el servicio militar (E 48,127), entonces se puede reconocer a la generación joven en Alemania como afectada de modo casi totalmente negativo. Grandes grupos, una parte entera de los jóvenes ciudadanos de nuestra Comunidad se sienten no comprendidos, frustrados o en desventaja. Las decisiones mencionadas "afectan", en parte existencialmente, a aquellos que también deben importar a la Constitución de una Comunidad: la juventud. La Constitución rige para favorecer. Un tribunal constitucional que en el resultado se sitúa, o parece situarse, tan frontalmente "en contra" de la generación joven con decisiones básicas, no puede eludir la cuestión del contrato 'generacional como una manifestación del contrato social. Aunque algo habla a favor de cada decisión individual del Tribunal Constitucional, en su suma se podria llegar tendencialmente a una carga insoportable (psicológica, material e inmaterial) de la generación que se está desarrollando. Asi pueden

49 La expresión alemana "vereinseitigende Setzungsideologien", entrecomillada en el original alemán, es dificilmente traducible, pero se refiere a aquellas ideologías que desconocen que la Constitución no es una simple y desnuda positivización de una decisión en el sentido del "decisionismo" (nota del Traductor).

50 Sobre ello, por ejemplo, Scheuner, Konsens und Pluralismus als verfassungsrechtliches Problem, en: Jakobs (coord.), Rechtsgeltung und Konsens, 1976, pp. 33 ss.; Isensee, NJW, 1977, pp. 545 ss.; Voigt (coord..), Der Herrschaftsvertrag, 1965.

51 Se alude al artículo 218 del Código Penal, despenalizador del aborto con arreglo al liamado "sistema de plazos", declarado inconstitucional por la Sentencia aludida, la primera sobre el aborto (nota del Traductor).

52 Sentencia sobre el rechazo en la función pública de personas que han estado vinculadas a organizaciones supuestamente contrarias al orden constitucional (nota del Traductor). 
verse amenazados los vínculos, que el Tribunal Constitucional Federal también tiene que estrechar permanentemente, entre la generación de los mayores, la más joven y la Constitución: podrian desgastarse o incluso romperse. Por lo menos, existe el peligro de dificultades de comprensión o déficits de comunicación. Con otras palabras, un tribunal constitucional, un "tribunal social en sentido lato" debe interpretar la Constitución "como contrato" interpretar de modo que posibilite a todos los ciudadanos sentirse comprendidos como tales, que ninguno se vea gravado excesivamente y no surja ninguna escisión o fractura entre los grupos o generaciones. Solo entonces es la Constitución, nuestra Ley Fundamental, el marco para el necesario y permanente "soportarse" 53 . siempre de nuevo todos los unos a los otros. El Contrat constitutionnel no puede perder a ningún grupo de ciudadanos o a alguna generación particular.

Esta tarea, ciertamente, no la tiene el tribunal constitucional solo. La salvaguardia y cautelosa actualización del convenio social de la Ley Fundamental no le obliga solo a él, pero sí le obliga también justamente a él. Están especialmente obligados a ello el legislador democrático, el Gobierno en la Federación y los Länder, los ayuntamientos, los otros tribunales y la opinión pública (pluralista) con sus grupos pluralistas, etc. ¡Su tan traido consenso es el "contrato" que aquí nos referimos $^{54}$ ! El Derecho constitucional se ha transformado en una parte del Derecho de la coexistencia. ¡La historia de Augsburgo $\left(¡ 1555 !^{155}\right)$ no es ajena a este aspecto!

En este trasfondo hay que examinar la jurisprudencia del Tribunal Constitucional Federal en conjunto y en sus detalles: sus decisiones deben ser plausibles también para generación joven; ésta debe poder "aceptarla". En el problema de los radicales, por ejemplo, debió desarrollarse una praxis procesal, que partiera de la confianza, no de la desconfianza ${ }^{56}$, entre el Estado y los ciudadanos jóvenes, así se justifica que la exigencia de adecuación y con ello el postulado de lealtad constitucional respecto de los aspirantes a acceder a la función pública sean universales. Dicho claramente: una diferenciación según las funciones no es posible. Apenas ningún ámbito es tan "sensible a la seguridad" como las escuelas: de ellas depende qué teoria constitucional nos podemos permitir en último término.

53 Aquí utiliza el autor un juego de palabras no traducible, pues emplea el verbo soportarse (Sich Vertragen), de gran similitud con la palabra contrato (Vertrag) (nota del Traductor).

54 Véase la indicación en mi contribución a la discusión en la Jornada de Profesores de Derecho Politico de Bonn, 1978 (VVDer SpiegeltRL, 1979, p. 128).

55 Parece aludir aquí el autor al año 1555, fecha en que se firmó la conocida como Paz de Augsburgo, que consagró la fórmula cuius regio, eius religio como solución, por el momento, a las guerras entre católicos y protestantes, entre la Reforma y la Contrarreforma, proclamada por el Papa Pablo III en el Concilio de Trento en 1546, siendo una fórmula que contribuia a consagrar el absolutismo de los principes protestantes. La referencia se explica, en todo caso, porque el presente articulo recoge una conferencia pronunciada por el autor en el Ayuntamiento de Augsburgo (Baviera) en 1978.

56 Sobre la discusión, Denninger, VVDer SpiegeltRL, número 37 (1979), p. 7 (30 ss.). 
b) El equilibrio de cargas arroja ejemplos positivos para la superación adecuada de las cuestiones constitucionales de la mano del modelo de contrato social y generacional: la gran prestación, ya histórica, de la postguerra. Tanto el legislador federal y el Ejecutivo con sus numerosas regulaciones subsiguientes como también la economia (nacional y de las empresas) afectada, y hasta cada ciudadano, ha prestado su contribución al logro de esta ejemplar obra comunitaria; el Tribunal Constitucional Federal ha allanado el camino jurídico-constitucional ${ }^{57}$. Se puede aquí hablar, en el mejor de los sentidos, de una "acción concertada" de todos los ciudadanos y grupos, de una acreditación afortunada del contrato social y generacional ${ }^{58}$, de una vinculación de todos, los unos con los otros.

Pero el contrato social tiene hoy también una actualidad específica para la vieja generación: ¡imenciono la palabra clave "contrato de pensiones"! Ni es posible gravar excesivamente a "los jóvenes" ni defraudar a "los viejos" en su confianza en la generación joven como "parte contractual". La generación joven tiene que pensar, por su parte, lo que han llevado a cabo los padres y madres en la época republicana de la reconstrucción. Se trata de la justicia de la prestación y la contraprestación entre las generaciones.

No es menos controvertido el modelo del contrato social en atención a la sobrecarga amenazadora de la generación joven por la deuda nacional o la energia nuclear. No solo la economía no puede ser "probada" hasta los límites de su capacidad de resistencia, tanto menos puede ser sobrecargado el futuro humano de las generaciones con riesgos injustificados. iLas partes del contrato social son no solo los vivos, sino tambiẹ́n los todavía no nacidos! A su favor existe un fideicomiso. Quizás haya ello que verlo hoy incluso globalmente, es decir, extenderlo a todo el bloque terráqueo de nuestro "planeta azul".

La sociedad mundial ${ }^{59}$ hay que verla en un "contrato mundial"; incluso si no existe de hecho ese contrato, hay que actuar como si existiera: en beneficio de toda la humanidad. Los pactos de derechos humanos de la Organización de Naciones Unidas son, en esta perspectiva, anteojos de larga vista.

Cfr. la sentencia sobre las ayudas a las inversiones: E 4, 7; de la jurisprudencia sobre cuestiones de equilibrio de cargas, véase BVerfGE 4,$60 ; 6,290 ; 9,305 ; 11,50 ; 11,64 ; 12,251 ; 12,180 ; 15,126 ; 15,328 ; 17,67 ; 18,441$; 19,$166 ; 19,354 ; 19,370 ; 20,230 ; 23,153 ; 23,288 ; 23,327 ; 32,111$, con voto particular de Rupp-v. Brūnneck 129 ss; $32,249$.

58 Véase también la Sentencia del Tribunal Constitucional Federal sobre el segundo caso sobre el numerus clausus (ajustado a las generaciones): ninguna exclusión de grupos enteros de aspirantes a estudiar una carrera (E 43, 291, 317, véase también 326).

59 Sobre ello, Sur, VVDer SpiegeltRL, número 36 (1978), p. 164 (Discusión). 
c.- La exposición detallada

Ciertamente, no todos los problemas se solucionan con esta propuesta de inserción de la jurisdicción constitucional en la función de garantía de la Constitución y el proceso permanente de actualización de su contrato social, pues puede quizás abrirse nuevamente la discusión sobre el fundamento y los límites de la jurisdicción constitucional -más allá del camino batido como "función política", función juridica, etc.

En particular, el tribunal constitucional tiene corresponsabilidad, no una responsabilidad él solo, respecto del contrato social constitucional, en especial el generacional. Tiene aquí sólo junto a otros, en especial junto al legislador democrático, un lugar especifico juridico-funcionalmente a él otorgado. El Tribunal Constitucional Federal no puede, por ejemplo, aprobar una regulación de las pensiones que grave o exonere a la generación joven o a la vieja de manera desproporcionada; "formalmente", se puede argumentar con el principio del Estado social, la dignidad humana, la protección de la confianza y el valor del trabajo, pero materialmente debería orientarse al modelo del contrato [social]. Los límites de la deuda nacional admisible hay que determinarlos en atención al contrato social entre las generaciones; en último término, este está detrás de una norma juridico-positiva como el artículo 111.2 de la Ley Fundamental (cfr. en general para el Derecho presupuestario: E 45,1). Otros ejemplos se pueden construir fácilmente (por ejemplo, en materia de protección medioambiental, formativa o en atención a la necesaria dinamización del subsidio público estatal familiar por hijos).

El círculo de los participantes en el contrato social y constitucional debe comprender, por tanto, a la sociedad abierta, no puede establecer la sociedad cerrada: los grupos marginales, los discapacitados, los grupos que no se pueden organizar o solo difícilmente pueden hacerlo (por ejemplo, los ancianos), corresponden a ello al igual que las minorías religiosas. El acceso debería permanecer tan abierto como fuera posible, así como, al contrario que la expulsión, la libertad de emigración deberia protegerse como derecho humano: ¡solo las sociedades totalitarias deniegan esta "rescisión" individual del contrato social!

El Tribunal Constitucional Federal, en el marco de su "jurisprudencia del pluralismo" 60 , tiene especial responsabilidad frente a los grupos mencionados. $\mathrm{Si}$, como se ha mostrado, hay que oír a los no nacidos, la sentencia del Tribunal Constitucional Federal sobre el articulo 218 del Código Penal $(E$ 39, 1) aparece también con una nueva luz. La Constitución, y el Tribunal Constitucional Federal como su "órgano", tienen un especifico deber de protección frente al nasciturus, al no nacido, pero engendrado. Quizás este planteamiento contribuya a apaciguar 
la discusión sobre la sentencia del Tribunal Constitucional Federal sobre el artículo 218 del Código Penal; podria hacerla algo más plausible para la generación joven. Esta comprende tan poco cómo ella misma está (simplemente) en una línea de continuidad de la historia, como individualidad inconfundible, pero al mismo tiempo en continuidad con las generaciones pasadas y con responsabilidad hacia las siguientes. Aqui es visible un contexto antropológico. La planeación y la politica educativas (el tema de Thomas Finkenstaedt) adquiere una nueva dimensión.

En una visión rápida de la participación del Tribunal Constitucional Federal en la conservación y cambio del contrato social (como factor operativo), en conjunto: en su acreditación, y reconociendo una responsabilidad colectiva de todos en este "contrato constitucional" (la reciente historia acredita cuántas Constituciones son un compromiso surgido históricamente y no algo "puesto" o "emanación" "1), resulta para el Tribunal Constitucional Federal (y mutatis mutandis para la jurisdicción constitucional de los Länder) lo siguiente:

En el juego recíproco de tradición y transformación, de cambio y conservación, el Tribunal Constitucional Federal tan pronto avanza, así en materia de protección de minorias (casos de los Testigos de Jehová), como retrocede considerablemente, por ejemplo en el ámbito económico. No puede "excluir" a generaciones enteras, o en su mayoria, de los procesos de desarrollo progresivo de la Constitución ni transformarse a sí mismo de Senado [Sala judicial] en "consejo de ancianos" (Seniorat), esto es, ver como parte del contrato social solo a los ancianos y vivos. Periodos de judicial activism y de judicial restraint se pueden suceder unos a los otros a la luz de una concepción del Tribunal Constitucional Federal iluminada por el contrato social: el Tribunal Constitucional Federal proporciona al respecto un buen material ilustrativo ${ }^{62}$. Sigue existiendo, en especial, el ámbito independiente del legislador democrático como primer poder.

En todo ello, el Tribunal Constitucional Federal es fuerza politica (también cuando "retrocede"), todo lo demás es autoengaño. Incluso cuando el Tribunal ejerce restraint, por ejemplo al no declarar inconstitucional una ley, actúa "politicamente"; también cuando, como en la sentencia de la televisión $(E$ 12, 205), a partir del artículo 5.1 de la Ley Fundamental, decreta amplias directivas en el sentido de "politica de directrices" respecto del pluralismo en el ámbito de la radiodifusión y la televisión, trabaja "juridicamente". ¡La alternativa "Derecho o Politica" se acredita como una pseudoalternativa! (1978), pp. 1 ss.

62 Sobre ello, Haller, Supreme Court und Politik in den USA, 1972, pp. 68 ss.; véase mi recensión en: Deutsches Verwal. tungsblatt, 1973, pp. $388 \mathrm{ss}$. 
En esta visión desde el contrato constitucional encaja el (nivelado) status activus processualis de grupos pluralistas ${ }^{63}$ al igual que la visión social conjunta del Derecho procesal constitucional. El Tribunal Constitucional Federal en sentido amplio, como "tribunal social" sui generis que hay que ver más allá del dogma de la separación del Estado y la sociedad, ya no aparece más como utópico. El status activus processualis constitutionis está en deuda, en primer lugar, con el ciudadano: el recurso constitucional de amparo que permanece abierto a cualquiera sin obligación de asistencia letrada es su genuino derecho fundamental desde el aspecto procesal, es una pieza nuclear del status activus processualis constitutionis. Pero la concepción especificamente jurídicoconstitucional del Derecho procesal constitucional conduce también a su significación como derecho de información pluralista y como derecho de participación para los grupos pluralistas; yo me refiero a la creciente praxis del Tribunal de dar la palabra en procesos constitucionales más o menos "grandes" a organizaciones como la DGB ${ }^{64}$, las confederaciones empresariales, otras federaciones y grupos. Ello es expresión de una concepción vinculada a la sociedad de la función del Tribunal Constitucional Federal como tribunal constitucional, esto es, como un tribunal que comprende al Estado y a la sociedad, lo que por ello también incluye las cualidades sustanciales de este conjunto.

C.- La jurisprudencia del Tribunal Constitucional Federal entre tradición y cambio, entre tradición y progreso

Veintisiete años de jurisprudencia del Tribunal Constitucional Federal. Esto obliga a plantear la cuestión de si la "tradición y el cambio" se reflejan en él, y cómo lo hacen, y la cuestión de si el "cambio" tiene un poco de "progreso" 65 . En el centro de las consideraciones se hallan dos problemas:

¿Hay progresos por medio del Derecho judicial constitucional, tiene el Tribunal Constitucional Federal una especifica función de progreso, teniendo lugar eventualmente el progreso alguna vez en contra, a pesar o sin el Tribunal Constitucional Federal?

63 Sobre ello, mis referencias en: Verfassung als öffentlicher Prozess, 1978, pp. 677 ss.

$64 \mathrm{DGB}=$ Deutscher Gewerkschaftsbund, esto es, Confederación alemana de sindicatos (nota del Traductor).

65 Se podria dudar si se puede hablar de "transformación" donde se trata de la construcción, esto es, de los primeros años desde la promulgación de la Ley Fundamental (1949) o desde el comienzo de la actividad del Tribunal Constitucional Federal (1951). Aún así, se puede tomar como parámetro la situación de la Constitución de Weimar de 1933. Por lo demás, la jurisprudencia se ha aferrado una y otra vez (positiva y negativamente) a las discusiones de Weimar: en perspectiva material y de contenido (cfr., para los derechos fundamentales, por ejemplo, E 7, 198, 209 ss; 7, 377, 413 ss.), pero también en perspectiva jurídico-procesal (cfr. las referencias en Juristenzeitung, 1976, p. 377, nota 4); en general, Scheuner, Festgabe BVerfG, tomo I, 1976, pp. 2 ss., sobre la tradición de la jurisdicción estatal alemana en los siglos XIX y XX. Su autocomprensión tiende puentes hacia Weimar, por más que la extensión de la jurisdicción constitucional bajo la vigencia de la Ley Fundamental sea de nuevo tipo y por más que aquella jurisdicción constitucional sea tan genuina. 
¿Cuáles son los instrumentos para el cambio o el progreso por parte del Tribunal Constitucional Federal (sentencias básicas, decisiones apelatorias, obiter dicta como anuncio de cambios jurisprudenciales, opiniones disidentes), que asi se transforma en un "contemporáneo del futuro?

Como respuesta a la pregunta 1):

a.- La cuestión preliminar interdisciplinaria

Entre paréntesis está la cuestión de si hay en principio un parámetro para el progreso en la ciencia del Derecho, en especial en la teoria del Derecho constitucional o cómo habria que obtenerlo. Aquí unas palabras sobre la cuestión preliminar, que es el tema interdisciplinario.

El problema del progreso posee dos aspectos: ihay progreso a través de la ciencia, en especial a través de la ciencia juridica? y ¿hay progresos en la ciencia, especialmente en la ciencia jurídica?

Antes hay que perfilar el concepto de progreso. Ello solo puede suceder a partir de un determinado sistema de coordenadas, en el que sean magnitudes decisivas la dignidad humana, la libertad y la igualdad (y con ello, resumidamente: los postulados de la democracia).

Ciertamente, existe fundamento para aplicar en el Derecho el concepto de progreso solo con muchas cautelas y mantener una medida colmada de desconfianza. El homenaje de $\mathrm{Tu}$ binga de 1977 a la "tradición y el progreso en el Derecho" ${ }^{\text {"6 }}$ ha traido esto a la memoria y ha subrayado las ambivalencias. A la luz de una comparación constitucional que se orienta a la Constitución "buena" del tipo del standard occidental, no pocas cosas de la jurisprudencia del Tribunal Constitucional Federal pueden valorarse, con toda moderación, como progreso.

Ciertamente, el progreso se puede apenas afirmar a lo largo de periodos largos, por ejemplo, en la comparación entre el Mundo Antiguo y la Edad Media o entre esta y la Edad Moderna. Pero también se puede perfectamente decir que, desde el comienzo del siglo XIX, en el curso de la conversión europea del Estado constitucional también en Alemania se lograron progresos por medio de la Ciencia juridica. Esta desarrolló fuerza directiva, no solo copió y comprendió. Hizo sus propios "descubrimientos" y tuvo sus propios "hallazgos": llevó a cabo prestaciones propias para la res pública. Ciertamente, no sin las otras ciencias, sino la mayoria de las veces mano a mano con ellas ${ }^{67}$, pero ocasionalmente también contra ellas, pero en todo caso bajo su

Sobre ello, mi recensión en: BayVBl, 1978, pp. 581 ss.

Cfr. BVerfGE 47, 46 (educación sexual). Un ejemplo negativo es la "decisión Solange", BVerfGE 37, 271, que está en contra de la opinión dominante de la ciencia. 
propia dirección y no sólo como su "mensajero" o "asistente de ejecución”. Así, el concepto jurídico de Estado de Derecho y de dignidad humana de la Ley Fundamental le debe no poco a la Filosofía del idealismo alemán (Kant). Pero la fórmula del objeto ${ }^{68}$ de Dürig fue entonces ciertamente una contribución propia genuinamente juridica.

La cuestión del progreso en la Ciencia del Derecho (en la que hay que incluir a la jurisdicción constitucional, en especial la de la Ley Fundamental) es algo más fácil de responder. Dentro de periodos delimitados (por ejemplo, desde la elaboración de la Ley Fundamental o desde el nacimiento y crecimiento del Estado constitucional), en la Ciencia del Derecho difícilmente puede negarse el progreso: se comprime entonces también en un cierto progreso del sistema en su conjunto a través de la ciencia.

Ejemplos de ello son los refinamientos de las funciones de los derechos fundamentales, el descubrimiento del principio del Estado social, el fortalecimiento de la idea de pluralismo, la construcción todavia pendiente del Derecho constitucional cultural y, no se olvide, la expansión de la jurisdicción constitucional y su Derecho procesal, y por último, el desarrollo progresivo del federalismo. Ciertamente, los desarrollos están ocasionalmente vinculados, en especial o incluso en general, con pasos atrás o conllevan costes elevados. La expansión del Estado social, por ejemplo, llevó a nuevos peligros para la libertad personal; los planeamientos estatales ponen en peligro, por ejemplo, la autonomía municipal. Los "progresos" apenas son procesos lineales, equivalen con frecuencia más a una procesión danzante ${ }^{69}$; pero, visto en conjunto, no pueden ser ignorados como procedimiento y objetivo de la técnica de las obras imperfectas (Popper).

Unas palabras sobre la relación de la Ciencia del Derecho con las otras Ciencias en este contexto. ¡Hoy todas las Ciencias son propiamente "Ciencias vecinas"; $\mathrm{Al}$ respecto hay relaciones y periodos de recepción, de equívocos, de cooperación, pero también de distancia o de olvido o ignorancia ${ }^{70}$. Con frecuencia, las Ciencias sociales tienen una ventaja frente a las Ciencias

Maunz-Dürig-Herzog-Scholz, Art. 1.1 de la Ley Fundamental, números marginales 34 y siguientes (Dürig); pero cfr. también BVerfGE 30, 1. [Nota del Traductor: según esta fórmula de Dürig, asumida por el Tribunal Constitucional y hoy ampliamente aceptada, la dignidad humana exige no tratar a la persona como mero objeto, como mero medio, como magnitud fungible].

69 Parece hacerse referencia a las procesiones danzantes de Echternach (Luxemburgo), que son peregrinaciones en honor de S. Willibrod y son únicas en Europa occidental (nota del Traductor).

70 La recepción de Luhmann en el ámbito de las Ciencias administrativas puede haber servido a éstas. El malen. tendido, la falta de conocimiento que el mismo Luhmann tiene y transmite del estado de desarrollo de la ciencia jurídico-constitucional, daña a ésta (cfr. ya mi crítica en: Juristenzeitung, 1966, pp. 454 ss.). Sobre la critica a Luhmann en lo que respecta al Derecho administrativo: W. Schmidt, Archiv des öffentlichen Rechts, 96 (1971), pp. 321 ss (327 ss.) e id., en: Grimm (coord..), Rechtswissenschaft und Nachbarwissenschaften, $1^{\text {a }}$ y $2^{\text {a }}$ ed., 1976, pp. 89 ss. (especialmente, 96 ss); para la teoria del Derecho, Esser, Vorverständnis und Methodenwahl, 2a ed., 1972, pp. 205 ss. 
del Derecho en el descubrimiento y formulación del problema. Ejemplos se manifiestan en la discusión sobre el principio de "publicidad" al igual que en la que gira en torno al problema de la participación ${ }^{71}$. Esta ventaja no deberia, no obstante, evitar retar a las Ciencias sociales, por su parte, a ver y reconocer el planteamiento de cuestiones genuinamente juridicas desde el principio como tales. Solo de este modo se crea paridad en el discurso interdisciplinario.

\section{b.- Progreso a través del Derecho judicial constitucional}

Unas palabras sobre la cuestión de los posibles progresos por medio del Derecho judicial constitucional, según una función específica de progreso del Tribunal Constitucional Federal. Para anticipar la tesis: el tema marco de nuestra serie de clases magistrales "Tradición y transformación" puede, en cualquier caso, admitir su variación, para el Tribunal Constitucional Federal (y también para el Tribunal Constitucional de Baviera), a la expresión "Tradición y progreso". Esta valoración positiva de las funciones del Tribunal Constitucional Federal resulta ya de muchas sentencias concretas. El Tribunal es algo más que una mera "cinta de transmisión" para innovaciones. En lo que se refiere al progreso por medio del Derecho judicial constitucional, puede haber también ámbitos en los que sea posible o necesario el progreso contra, a pesar, o quizás sin el Tribunal Constitucional Federal ${ }^{72} \mathrm{o}$ en los que deba ser evitado ese progreso por el Tribunal (por ejemplo, por medio de la casación de "Leyes de reforma").

$\mathrm{Al}$ igual que la jurisprudencia en general ${ }^{73}$, la jurisdicción constitucional puede conseguir un "hallazgo" o tener éxito en un "descubrimiento", aunque sea simplemente en el modo en que se reciben los hallazgos o descubrimientos de la Ciencia. Ejemplos de ello son el reconocimiento de un nuevo instituto muy politico: el de la lealtad constitucional, siguiendo a Rudolf Smend ${ }^{74}$; o la estructuración del artículo 5 de la Ley Fundamental en la sentencia sobre la televisión. Aqui "se comprenden las épocas en el pensamiento jurídico", "se equilibran, se fundamentan plausiblemente y se satisfacen los intereses contrapuestos del conjunto constitucional" asi un desarrollo ulterior de la sentencia de la televisión en atención a las nuevas técnicas mediáticas puede ser imperioso ${ }^{75}$.

La jurisdicción constitucional es, en igual escasa medida que la Ciencia del Derecho, un mero "rezagado" frente a la realidad politica: tiene la competencia y la fuerza para la dirección, para la

71 Sobre ello, Habermas, Strukturuandel der Öffentlichkeit, 9a ed., 1978, por un lado (cfr. también P. Häberle, Öffentlichkeit und Verfassung, 1969, ahora en: Verfassung als öffentlicher Prozess, pp. 225 ss.; Schmitt Glaeser, VVDer SpiegreltRL, número 31 (1973), pp. 179 ss, por otra parte.

72 Sobre todo en el ámbito parlamentario de la democracia y en su proceso político.

73 Sobre ello, Larenz, Kennzeichen geglückter richterlicher Rechtsfortbildungen, 1965; Dölle, "Juristische Entdeckungen", Verh. 42, DJT, 1959, tomo II, B I ss.

74 Cfr. E 12, 205 (254).

75 Cfr. ya E 31, 314 (326); Geiger/Rinck/Wand, p. 337 (338). 
mejora (limitada) de esta realidad. Un ejemplo significativo es la decisión sobre la igualación de los niños no matrimoniales con los matrimoniales (sobre el artículo 6.5 de la Ley Fundamental: E 25,$167 ; 44,1,17$ ss.), una corrección de la realidad social de la "moral burguesa". La sentencia de la televisión es una parte de la moral federal, planteamiento de una teoria de la acción politica: el proceso justo entre la Federación y los Länder como una parte de la buena ética politica, hace bien poco en el cuestionable proceder del Gobierno Federal en el llamado "Mängelbericht" Menciónese la sentencia del caso "Lebach" (E 35, 202), en el que se prohibió a la cadena de televisión ZDF la emisión de un programa en interés de la resocialización de un prisionero. En estos ejemplos yace, no en último término, una función cultural del Tribunal Constitucional Federal, con lo cual todavia habría que aclarar los conceptos "cultura" y "función"

En el ámbito del Derecho procesal constitucional, hay que mencionar el gran avance en el refinamiento de la garantía procesal de la tutela judicial del artículo 19.4 de la Ley Fundamental en relación con el principio de la audiencia jurídica (articulo 103.1 de la Ley Fundamental ${ }^{77}$ ), al igual que la praxis progresiva de practicar el Derecho procesal constitucional como Derecho de participación pluralista y así crear la posibilidad de demandas colectivas fácticas encubiertas.

Ciertamente, un tribunal constitucional no se puede contraponer a la larga con éxito, sin puesta en peligro de su autoridad, a los grandes cambios de una comunidad libre, como lo prueba la historia de los Estados Unidos de Norteamérica ${ }^{78}$. Al contrario, no puede ser tampoco un adelantado sin la base de los desarrollos ideales y materiales que subyacen en lo profundo de la comunidad. Sin embargo, el tribunal constitucional puede acelerar (o retrasar) muchas cosas. Sus cambios de agujas tienen efecto configurador para la tradición y la transformación, para la tradición y el progreso.

La función de progreso del Tribunal Constitucional Federal tiene limites: estriban en su equilibrio con las otras funciones estatales, con las cuales se halla en competencia, sobre todo con el legislador democrático y otras funciones de la Constitución como proceso público (estructurado) o su paralelogramo de fuerzas: hace poco, sobre todo en los pronósticos.

Como respuesta a la pregunta 2):

c.- Los instrumentos para la transformación y el progreso por medio del Tribunal Constitucional Federal

76 Sobre ello, Kloepfer, "Die Mangel des 'Mängelberichts', ZRP, 1978, pp. 121 ss.

7 Recientemente, E 46, 166 (177 ss.) y 46, 185, 202; 47, 182; finalmente, 51, 150 (156 ss), 268 (284 ss.).

78 Cfr. el aforismo: "The supreme court follows the elections", sobre ello P. Häberle, "Zeit und Verfassung" (1974), ahora en: Verfassung als öffentlicher Prozess, pp. 59 ss. (74). 
¿Cuáles son los instrumentos para la transformación y el progreso a través del Tribunal Constitucional Federal? En primer lugar, están las decisiones básicas, que en absoluto deben estar siempre "preparadas" 79 ; además, los obiter dicta, por ejemplo: el anuncio de cambios jurisprudenciales ${ }^{80}$; en una visión más de cerca, el Tribunal Constitucional Federal ha creado, con el instrumental nivelado de las consecuencias de las leyes inconstitucionales, un "resorte" diferenciado para la "organización" del cambio ${ }^{81}$ ("jurisprudencia de reforma").

La opinión disidente (articulo 30.2 de la Ley del Tribunal Constitucional Federal) es considerada en el eje temporal un instrumento sobresaliente para el anuncio y realización de cambios y para aferrarse a la tradición. Porque esta opinión disidente lleva a la confrontación de argumentos en lugar de a su ocultamiento. Ello lo confirman la historia y el presente de la Supreme Court de los Estados Unidos de Norteamérica ${ }^{82}$. Al Tribunal Constitucional Federal no hay que tomarlo a este respecto como una unidad y sí considerarlo de modo que la tradición y el cambio puedan estar "repartidos" en la misma Sala (o en ambas Salas). Un ejemplo negativo de la evitación de la publicidad es la práctica excesivamente floreciente del Tribunal Constitucional Federal sobre la interpretación conforme a la Constitución (por ejemplo, E 47, 327), que en el fondo acaba un poco en una demanda preventiva de omisión o en un control normativo desproporcionados; también merece critica la "ideología del precedente" del Tribunal Constitucional Federal (por ejemplo, E 36, 1, 2 ss).

d.- Posibilidades y limites de la funcionalidad del Tribunal Constitucional Federal en el marco de la cultura politica del ordenamiento básico liberal-democrático de la Ley Fundamental

La última pregunta sobre las posibilidades y limites del Tribunal Constitucional Federal en el marco de la cultura política del ordenamiento básico liberal democrático de la Ley Fundamental nos hace regresar al punto de partida. Lo que el Tribunal Constitucional Federal, en un tiempo relativamente breve, ha llevado a cabo juridicamente, para y por medio de juristas, hay que valorarlo positivamente; y no menos lo que ha contribuido al proceso político: en parte iniciándolo, en parte excitándolo ("con política de directivas").

Cfr., por ejemplo, la primera sentencia sobre financiación de los partidos políticos (BVerfGE 20, 56) en relación a E 8, 51 (63); E 24, 300 con relación a E 20,56; en parte, también la sentencia sobre el deber de realizar el servicio militar, E 48, 127 en relación a E 12,45 .

Sobre el problema, P. Häberle, Juristenzeitung 1977, p. 361 (367 ss.).

81 Cfr., por último, Moench, Verfassungswidriges Gesetz und Normenkontrolle; sobre ello, véase mi recensión en Deuts. ches Verwaitungsblatt, 1978, pp. 653 ss; Pestalozza en: Festgabe BVerfG, tomo I, 1976, pp. 519 ss.

82 Cfr. Haller, Supreme Court und Politik in den USA, 1972, pp. 66 ss., 341, sobre ello, véase mi recensión en Deutsches Verwaltungsblatt, 1973, pp. 388 ss. 
La cuestión es, simplemente, si, y en qué medida, el Tribunal se exige a si mismo y al conjunto del sistema demasiado a la larga, si no debe -y puede- ahora contenerse en mayor medida después de los resultados constructivos en el campo de los derechos fundamentales y de la politica del Estado federal de las primeras décadas, sobre todo frente al legislador democrático, para no coartar demasiado, o "echar a perder", la cultura político-democrática desde la justicia del Estado de Derecho.

¡La jurisdicción constitucional no es, a fin de cuentas, ni un seguro de vida juridico ni políti$\operatorname{co}^{83}$ ! Su desarrollada concepción política y pluralista está ligada internamente a toda la cultura de nuestra República. Ello la dota de funciones positivas, pero conduce también a limites ${ }^{84}$. Esto merece algunas consideraciones.

La jurisdicción constitucional ya desarrollada es, como el federalismo, parte de la cultura politica, especialmente en los EEUU, al igual que ahora en Alemania. La "cultura política" 85 es aquí entendida como un concepto complejo (empírico-normativo), no como ningún esquema libre de valores. Puede ser alumbrado a través de investigaciones demoscópicas sólo muy puntualmente (Theo Stammen). La "cultura política" ciertamente abarca a las ideas subjetivas, experiencias y expectativas de los ciudadanos con relación a las instituciones de su sistema (en tanto que "constitución interna" de un pueblo); pero a ella corresponde también su actuación objetivada, corresponde el comportamiento de los responsables politicos, la praxis parlamentaria, también la función de los tribunales, corresponde el grado de realidad de la libertad individual y de pluralismo vivido, corresponden temas y asuntos, desde la carta al director hasta las iniciativas ciudadanas, desde la entrada en un sindicato hasta la pertenencia a una confesión religiosa y a una asociación de artistas, desde la compra y lectura de libros hasta el estudiar como elementos de la cultura constitucional vivida. El Tribunal Constitucional Federal alemán ha realizado par excellence una parte del "trabajo de educación y formación política" ("pedagogía constitucional", principios constitucionales "como" objetivos educativos) en el campo de los derechos fundamentales, pero también en el del federalismo con sus máximas sobre el actuar de los órganos constitucionales unos respecto de otros (palabras-clave: "lealtad federal", consideración reciproca de los órganos constitucionales unos respecto de otros -cfr. BVerfGE 12,205 [254ss.); 35,193, (199); 36,1 (15); 45, 1 (38ss.)]. Precisamente si no se puede "implantar"

83 Así, parafraseando unas palabras de Ehmke [VVDer SpiegeltRL, número 20 (1963), p. 53 (72)].

84 Un límite de la jurisdicción constitucional se deriva también de que solo actúa a instancia de parte, no de oficio. Debe ser *incitada" por los ciudadanos o fuerzas politicas".

85 Sobre el concepto, D. Berg-Schlosser, Politische Kultur, 1972. Véase, básicamente: L. W. Pye/S. Verba, Political Culture and Political Development, 1965; G.A. Almond/S. Verba, The Civic Culture, 1963; W. A. Rosenbaum, Political Culture, 1975; P. V. Dias, "Der Begriff 'Politische Kultur' in der Politikwissenschaft", en: D. Oberndörfer, Systemtheorie, Systemanalyse und Entwicklungsländerforschung, 1971, pp. 409 ss.; K. v. Beyme, 'Politische Kultur' und 'Politische Stil' en: id. (ed.), Theory and Politics, Festschrift für C. J. Friedrich, 1971, pp. 352 ss. 
la cultura política (al igual que el Estado de la cultura) de la noche a la mañana, corresponde a la jurisdicción constitucional un papel central en este lento proceso de crecimiento como lo es el de la Constitución.

La fuerte raigambre ético-civica y público-civica de la jurisdicción constitucional, en especial del recurso constitucional de amparo, su función de identificación en la relación de los ciudadanos y la Constitución y, por ello, su contribución a la constitución de la cultura política, oculta un aspecto negativo: la jurisdicción constitucional de la Ley Fundamental de Bonn también puede indicar una desconfianza apolitica contra la democracia y una confianza desproporcionadamente grande en la jurisprudencia. El pensamiento alemán sobre la jurisdicción constitucional no puede tornarse en falta de fe en la democracia. Dicho de otro modo, la actual relación positiva con la jurisdicción constitucional no debería absolutizarse; no puede tener su correspondencia reversa, al otro lado del espejo, en una relación negativa con el pluralismo de intereses, con las (necesarias) situaciones delimitadas de conflicto, con las funciones propias del proceso politico democrático abierto o recrudecerse en una falta de relación, como en las "bellas letras". Esta consideración remite a la pluralidad de tareas que quedan al politico, al funcionario, al educador, al literato republicano, al ciudadano, a todos nosotros con relación a nuestro orden de libertad, sin privar al Tribunal Constitucional Federal de nada de su esplendor. ¡No solo la jurisdicción constitucional, todos nosotros somos, politicamente, "guardianes de la Constitución"! 